\title{
Pragmática histórica del español: una primera aproximación al estudio de actos directivos en cartas privadas (S.XIX-S.XXI) ${ }^{1}$
}

\author{
Historical pragmatics of Spanish: a first approach \\ to the study of directive speech acts in private \\ letters $\left(19^{\text {th }}-21^{\text {st }}\right.$ Centuries)
}

\author{
Paula Albitre Lamata \\ Universidad Complutense de Madrid / Instituto Universitario Menéndez Pidal, \\ Madrid, España \\ palbitreaucm.es
}

\section{ACCESO ABIERTO / OPEN ACCESS}

Cita: Albitre Lamata, Paula (2021). Pragmática histórica del español: una primera aproximación al estudio de actos directivos en cartas privadas (S.XIX-S.XXI). Textos en Proceso, 7(1), pp. 38-59. https://doi.org/10.17710/tep.2021.7. 1.3 albitre

Editoras: Esperanza Alcaide Lara (Universidad de Sevilla) y Ana Pano Alamán (Università di Bologna)

Recibido: 15/10/2020

Aceptado: 20/05/2021

Conflicto de intereses: La autora ha declarado que no posee conflicto de intereses.

Copyright: (c) Paula Albitre Lamata. Esta obra está bajo licencia $\underline{\text { Creative }}$

Commons Reconocimiento 4.0

\section{Resumen}

Este artículo aborda la evolución de los actos directivos en cartas privadas de los siglos XIX, XX y XXI. Para ello, utilizando como corpus treinta cartas privadas, se analizan tanto las formas en las que se manifiestan los actos directivos en diferentes períodos históricos como sus situaciones de aparición en el género epistolar. Los resultados de este estudio constatan un descenso progresivo en el uso de expresiones directas, especialmente del imperativo, en favor de formas convencionales indirectas, como las aserciones volitivas y desiderativas. Todo esto parece apuntar a una distinta atribución de valores de cortesía a las estrategias (in)directas a lo largo de la historia.

Palabras clave: pragmática histórica, (des)cortesía histórica, actos de habla, género epistolar, historia de la lengua española, lingüística de corpus.

\section{Abstract}

This paper aims to analyse the evolution of directive speech acts in private letters of the nineteenth, twentieth and twenty-first centuries. In order to do this, by using a corpus of thirty private letters, it analyzes both the ways in which the directive speech acts are manifested in different periods and their situations of appearance in

\footnotetext{
${ }^{1}$ El estudio forma parte de la investigación realizada en el marco del proyecto de investigación titulado "Variación pragmática en la expresión de la cortesía en español" financiado por UCM-Grupo Santander (REF PR87/19-2254), así como del I+D+i titulado "Los procesos de la gestión de la imagen y la (des)cortesía: perspectivas históricas, lingüísticas y discursivas" (PID2019-107668GB-I00), dirigidos por las doctoras Iglesias Recuero e Hidalgo Downing.
} 
the epistolar genre. The results suggests a decrease in the use of direct expressions, especially the imperative, over time, in favor of indirect conventional forms such as volitive and desiderative assertions. All of this seems to point to a different attribution of courtesy values to (in)direct strategies throughout history.

Keywords: historical pragmatic, historical politeness, speech act, epistolary genre, history of the Spanish language, corpus linguistics.

\section{Historia de los actos de habla en español}

Durante las últimas décadas la pragmática histórica ha despertado un gran interés dentro del ámbito de investigación hispánico; de ello es prueba la creciente publicación de interesantes trabajos sobre aspectos históricos del discurso ${ }^{2}$. Esto ha permitido un avance importante en el conocimiento de la historia de los actos de habla y de la (des)cortesía en español ${ }^{3}$.

Sin embargo, a pesar del evidente desarrollo metodológico y teórico de los estudios sobre pragmática histórica del español, estos aún permanecen a la sombra de los trabajos realizados desde una perspectiva sincrónica. En este sentido, resulta ya por todos conocida la problemática suscitada por la base metodológica y las fuentes documentales en los estudios pragmáticos, más aún en los de corte diacrónico.

Si bien la investigación en pragmática sincrónica se basa en transcripciones de conversaciones reales, extraídas a partir de cuestionarios, encuestas o grabaciones, la investigación en el ámbito diacrónico debe acudir, obligatoriamente, a textos escritos. Ante esta dificultad, los autores han acudido a diferentes tipologías textuales para conformar sus corpus, tanto literarias (obras de teatro y ficción épiconovelesca) como no literarias (cartas y billetes privados, esquelas, tratados médicos, textos periodísticos o documentos jurídico-administrativos). Independientemente de la tipología textual con la que trabaje, el investigador en pragmática diacrónica debe reconstruir el contexto social a partir de datos históricos, pues no posee un conocimiento de primera mano ni de factores personales -estratificación social, relación entre los interlocutores- ni discursivos -tema, lugar, objetivo y tipo de comunicación-, datos que sí están a disposición del investigador en pragmática sincrónica.

En consecuencia, la pragmática histórica debe desarrollar sus propios principios metodológicos para así atender debidamente a las modificaciones y

\footnotetext{
${ }^{2}$ Para un recorrido más amplio y detallado por los estudios de la pragmática histórica en español, desde su origen hasta 2020, cf. Albitre Lamata (2020).

${ }^{3}$ Entre los trabajos más destacados sobre la historia de la formulación de los actos de habla y la (des)cortesía del español podemos mencionar los siguientes: Wesch (1996), Schrott (2000), Haverkate (2001), Moreno González (2002, 2008), Herrero Ruiz de Loizaga (1999, 2007 y 2013), King (2010 y 2012), Bustos Gisbert (2007), Bustos Gisbert e Iglesias Recuero (2003), Fuentes Rodríguez (2010), Fuentes Rodríguez y Alcaide Lara (2008 y 2009), Iglesias Recuero (2010, 2016, 2017 y en prensa), Carrera de la Red (2013), Carrera de la Red y Herrán Santiago (2007), Leal Abad (2011), Pons y Octavio de Toledo (2016), Cruz Volio (2017), Gancedo Ruiz (2018, 2019 y 2020), Helfrich y Pano Alamán (2018), Martínez Pasamar (2019), Martínez Pasamar y Tabernero Sala (2019), Tabernero Sala (2010, 2019), Albitre Lamata (2019), Bello Hernández (2019), Brenes Peña, Fuentes Rodríguez y González Sanz (2020), entre otros.
} 
cambios de cada época. Aunque las teorías actuales nos puedan ayudar a estudiar una determinada diacronía, no podemos recurrir exclusivamente a la observación del presente para explicar cambios pasados pues puede que estos no estén condicionados por los mismos factores lingüísticos y extralingüísticos que los fenómenos de variación actuales.

En este artículo adoptamos una orientación pragmalingüística (Leech, 2014) para realizar un estudio de los mecanismos de (des)cortesía en cartas privadas de amor, en concreto del acto directivo de petición y sus estrategias de atenuación e intensificación. Específicamente, nuestro período temporal estudiado abarca desde las últimas décadas del siglo XIX hasta el año 2020. A lo largo de este trabajo analizamos tanto las formas en las que se manifiesta en diferentes períodos un acto de habla determinado -acto directivo- como sus situaciones de aparición en un género discursivo concreto -la carta privada de amor-. De esta forma, y siguiendo la clasificación ${ }^{4}$ de Jacobs y Jucker (1995, p. 13), este artículo su ubica en la categoría de pragmática diacrónica, cuya atención se dirige hacia "el inventario lingüístico y sus usos comunicativos a lo largo de las etapas históricas de una misma lengua".

Nuestro objetivo es contribuir a inventariar y describir las formas lingüísticas empleadas para realizar actos directivos en cada época, así como explicar los factores lingüísticos y extralingüísticos -sociales, culturales y discursivos- que influyen en la elección de unas u otras formas y en su posterior convencionalización.

Seguimos así las sugerencias de Cano Aguilar (1995), que hace ya 25 años insistió en la necesidad de entrecruzar los caminos de la Pragmática lingüística y la Historia de la lengua española. Aunque todavía queda mucho por recorrer en esta disciplina, los avances en la historicidad de los actos de habla son notables gracias a los estudios realizados sobre distintas tipologías textuales, tanto literarias (Moreno González, 2008; Iglesias Recuero, 2010 y 2016; Cruz Volio, 2017; Gancedo Ruiz, 2019; entre otros) como no literarias (Wesch, 1996; King, 2010 y 2012; Tabernero Sala, 2010 y 2019; Iglesias Recuero, 2017; Carrera de la Red, 2013; Martínez Pasamar, 2019; entre otros).

El resultado principal de estos estudios es que, efectivamente, el contexto determina los valores sociales de las formas lingüísticas, y, por tanto, su uso y su interpretación tanto en situaciones prototípicas como no prototípicas. Esta variación en el uso se observa, por ejemplo, en el catálogo de formas disponibles para los hablantes de cada época. Mientras que el español áureo se caracteriza por la ausencia de formas convencionales indirectas, como las interrogaciones con poder o las cuasi-fórmulas relativas a la disposición del destinatario (Moreno González, 2003; Iglesias Recuero, 2010 y 2016), el español actual presenta de manera habitual dichas expresiones.

\footnotetext{
4 Según Jacobs y Jucker (1995) la pragmática histórica se subdivide en dos categorías: la pragmafilología y la pragmática diacrónica. La primera subdisciplina se centra en estudiar los aspectos contextuales de los textos históricos, incluyendo "las relaciones interpersonales y sociales entre los emisores y sus destinatarios, los factores sociales de la producción y recepción de los textos, así como los propósitos de estos" (Jacobs y Jucker, 1995, p. 11).
} 


\section{La carta privada como fuente documental de la pragmática histórica} Hoy, el valor de la carta privada para el estudio de la historia de la lengua es ya incuestionable. Testigo de sucesivos cambios sociales, este subtipo epistolar nos permite trasladarnos a otras épocas para conocer sus costumbres, redes y vivencias emocionales. Sus textos nos acercan a lo inmaterial de la realidad sacando a la luz infinidad de experiencias cotidianas, de formas de vida y de maneras de entender el mundo, algunas conformes a los usos oficiales y otras muy distantes.

A lo largo de los siglos, la carta ha permitido la comunicación entre personas a pesar de la distancia, posibilitando la transmisión de sentimientos e incluso estrechando relaciones y vínculos sociales. De ahí se deriva su tópico clásico de "conversación entre ausentes". Si bien cada carta tiene sus propios motivos e intereses, todas poseen un rasgo en común: la distancia entre sus interlocutores ${ }^{5}$.

Precisamente, la necesidad de aliviar la nostalgia por la distancia fue lo que propició el resurgimiento de las cartas privadas a finales del siglo XVII. Sin embargo, será en la Ilustración cuando asistamos a un auténtico 'boom' epistolar, que perdurará hasta finales del S. XX. El incremento de alfabetización de la población, las mejoras en la red de correos y de comunicaciones y los desplazamientos de población acarreados por las guerras, la política o el sueño americano repercutieron directamente en este incremento exponencial de la correspondencia personal. En la actualidad, el correo electrónico y los sistemas de mensajería instantánea (WhatsApp, Telegram, Instagram, Twitter, Facebook, etc.) han provocado la transfiguración de la carta, sustituyendo el tradicional soporte de papel por una pantalla. Antes, ya lo habían hecho la postal, el telégrafo y el teléfono. Sin embargo, y a pesar de esa desmaterialización, el correo electrónico actual aún mantiene algunas de las características de la carta, mayormente estructurales, por lo que continúa perpetuándose la estabilidad del género.

Así pues, las características más reconocibles de esta variedad epistolar, heredera del sermo familiaris ciceroniano, son:

1) Temática: asuntos personales e íntimos -salud, visitas, política, negocios- tratados con un tomo familiar. A partir del siglo XIX, y bajo la influencia del espíritu romántico, proliferaron las cartas de amor. Esta correspondencia no solo contenía felicitaciones, consejos y recomendaciones, también incluía órdenes y reprimendas.

2) Interlocutores: familiares o amigos que se escriben confidencialmente. Estas cartas suelen estar dirigidas a un único destinatario y ser bidireccionales, ya que las respuestas se enviaban de manera fluida y constante entre los corresponsales.

3) Estilo: sencillo, natural, espontáneo, directo; reflejado ya en algunos manuales de cartas de los siglos de Oro y posiblemente influido por el modelo francés de Madame de Sévigné.

4) Formato: soporte sencillo, caligrafía natural, márgenes escasos, frecuencia de errores y de la posdata.

\footnotetext{
${ }^{5}$ En el siglo XIX la distancia se logra suplir gracias a los medios fotográficos. A partir de ese momento, el envío de fotografías junto a la correspondencia se convertirá en una constante.
} 
5) Finalidad: mantenimiento, cohesión y fortalecimiento de una red social de parentesco o amistad. A través de las misivas, sus interlocutores cosieron hilos en la distancia para preservar su vínculo afectivo.

Es innegable que el lenguaje epistolar, y más el de la correspondencia privada, presenta rasgos de la oralidad, conectados con la teoría del diálogo y de la conversación, pero no se debe olvidar que compone un texto escrito, organizado y meditado. Aunque la carta sea considerada por muchos un elemento híbrido entre el hablar y el escribir y catalogada por otros tantos como un diálogo diferido, resulta inviable hallar la lengua oral directamente en estos documentos. Pedro Salinas (1948, p. 30) apuntó certeramente que "cartearse no es hablarse, asimilar escritura epistolar a conversación es desentenderse de la originalidad pasmosa con que aumenta la carta este negocio de las relaciones entre persona y persona". La carta, más allá de configurar una interacción conversacional entre dos sujetos, constituye un género textual con sus propias estrategias discursivas y retóricas. Tras la aparente sencillez o espontaneidad de la correspondencia privada, se esconde un complejo trabajo de elaboración, que en ocasiones implicaba autocorrecciones, cambios, copias y borradores. En definitiva, en la escritura epistolar no se deja nada -o casi nada- al azar.

Cabe señalar que son numerosas las ventajas que los epistolarios privados presentan a la hora de estudiar la pragmática desde un punto de vista histórico. Una de las características que avalan su uso en este tipo de estudios es su capacidad de radiografiar el contexto social de cada momento. Las cartas guardan la memoria gráfica de sus corresponsales y son la huella visible de las desigualdades sociales en el acceso y uso de la escritura (Castillo Gómez, 2014, p. 26). La tipología epistolar privada contiene numerosas referencias del eje temporal de la composición, incluyendo alusiones a la situación social y económica del remitente, información sobre su estado físico y anímico e incluso detalles sobre las costumbres y la vida cotidiana. Recordemos además que las cartas debían respetar las reglas y convenciones sociales coetáneas, especialmente a través de tratamientos y cortesías, lo que facilita la reconstrucción de la sociedad de cada momento histórico ${ }^{6}$. Pero debemos ir más allá de esta concepción de las cartas porque, de la misma manera que las redes de sociabilidad influían en la escritura epistolar, esta ayudaba a modelarlas. La correspondencia -y en general la escritura- no es solo un reflejo del entramado social en el que se produce, sino que también es un elemento capaz de modificarlo.

Fundamental también para su estudio pragmático es la presencia de dos interlocutores en el proceso comunicativo, uno presente -el remitente- y otro ausente -el destinatario. La carta siempre debía retratar la imagen personal del remitente para proyectarla en el destinatario y así salvar la separación física. Pero la escritura epistolar aporta datos sobre ambas figuras: no solo constituye una forma

\footnotetext{
${ }^{6}$ De hecho, la Pragmática de 1586 incluía una indicación expresa para el uso de los tratamientos en las cartas privadas.
} 
de creación de la identidad del sujeto y de afirmación de su lugar social, sino que también es el reflejo de la persona a la que van dirigidas ${ }^{7}$.

Además, su precisa ubicación espacio-temporal y su finalidad utilitaria facilitan en gran medida el estudio de la (des)cortesía histórica. En general, estos materiales son originales ${ }^{8}$ y presentan la fecha de redacción lo que permite reconstruir parcialmente el contexto. De hecho, al tratar asuntos de la esfera íntima, en las cartas privadas se incrementa el grado interaccional respecto a otro tipo de misivas, ya que el emisor se implica en mayor medida e implica también más al destinatario (Carrera de la Red, 2013, p.18).

Pero la correspondencia privada también tiene sus desventajas. El principal obstáculo que supone trabajar con este tipo de documentación es su conservación y recuperación, pues lo más común era que se mantuviese en la confidencialidad y que se destruyese por su carácter efímero. La mayoría de las cartas privadas que nos han llegado pertenecen a autores de estratos socioeconómicos superiores, ya que sus epístolas forman parte de catálogos de bibliotecas y archivos particulares. Por el contrario, las escasas cartas de los grupos sociales inferiores que se han conservado lo han hecho como materia probatoria en procesos inquisitoriales, pleitos civiles, expedientes de pasajeros a Indias o contenciosos eclesiásticos por incumplimientos matrimoniales. Por eso, el estudio pragmático-histórico de las cartas requiere tiempo y una metodología específica, que debe incluir:

a) un trabajo interdisciplinar entre historiadores y filólogos.

b) una evaluación del grado de conservación de los documentos.

c) unas coordenadas espacio-temporales para acotar y situar el objeto de estudio.

d) una representación lo más amplia posible de las variedades diastráticas del momento, para evitar el carácter 'unidimensional' de las fuentes de estudio.

e) una reconstrucción de las redes sociales de los interlocutores (sector social al que pertenecen, grado de distancia, tipo de relación y motivo de la carta).

\section{Objeto de estudio, corpus y metodología}

Nos proponemos estudiar las formas que adoptan los actos directivos de petición y orden en treinta cartas privadas, comprendidas entre los años 1889 y 2020. Todas las cartas que conforman el corpus tienen un rasgo en común: la relación entre el emisor y el destinatario es simétrica y de cercanía, pues entre ellos mantienen un

\footnotetext{
${ }^{7}$ Así, en las cartas de un mismo autor podemos encontrar notables diferencias dependiendo de quién sea el destinatario a quién se dirija. Los tratamientos y la cortesía serán más rígidos al dirigirse a superiores y más desenvueltos cuando su destinatario sea un familiar. Por eso es fundamental analizar el grado de distancia social y el tipo de relación (simétrica o asimétrica) existente entre las dos partes implicadas.

${ }^{8}$ De su finalidad puramente utilitaria se deriva su carácter de texto único -el ejemplar original enviado por el remitente al destinatario-, por lo que no es necesario dar a conocer a un gran público y no se reproduce en reiteradas ocasiones a lo largo del tiempo como sí ocurre con ciertos textos literarios (Palander-Colin y Nevala, 2005; Ramírez Luengo, 2016; Blas Arroyo, 2019).
} 
vínculo sentimental (pareja, matrimonio o relación extramatrimonial). Además, todas ellas han sido manuscritas por su remitente ${ }^{9}$.

Se han seleccionado diez cartas de cada siglo, con el fin de poder establecer comparaciones entre cada etapa ${ }^{10}$ :

- S.XIX: cinco cartas escritas por Emilia Pardo Bazán y dirigidas a Benito Pérez Galdós durante su relación extramatrimonial. También se han seleccionado cinco cartas de Delmira Agustini a su entonces esposo Enrique Job, catalogadas como correspondencia secreta por su propia autora.

- S.XX: diez cartas de Pablo Neruda a Matilde Urrutia, su última esposa. En concreto, las cartas analizadas fueron escritas durante su noviazgo secreto mientras él todavía estaba casado con Delia del Carril.

- S.XXI: diez cartas escritas por los participantes ${ }^{11}$ (cinco por chicas y cinco por chicos) del programa de telerrealidad español 'La isla de las tentaciones'. Estas cartas suponen la única vía de contacto entre las parejas durante su estancia en el programa, ya que la organización no les permite comunicarse de ninguna otra forma.

Debemos precisar que nuestro corpus es limitado en tres aspectos: i. en el número de textos analizados -insuficiente para poder realizar generalizaciones en el uso de los actos directivos-, ii. en la pertenencia de todos ellos a un solo género discursivo - el epistolar- y iii. en la falta de variedad de circunstancias interlocutivas y relaciones interpersonales -todas son simétricas y de proximidad-. Aun así el número de intervenciones que contienen un acto directivo asciende a 116 . Precisamente, el hecho de trabajar con un corpus limitado nos permite realizar un análisis cualitativo y cuantitativo de las estructuras lingüísticas empleadas en la realización del acto directivo y comparar su grado de convencionalización a lo largo de los siglos.

Como acto directivo entendemos todos aquellos enunciados mediante cuya emisión el hablante intenta que el destinatario realice una acción, beneficiosa para el hablante o considerada necesaria para él, y que presupone que el destinatario no llevaría a cabo de no mediar dicha emisión (Searle, 1969; Haverkate, 1994; Leech, 2014). Esta definición debe ser entendida a partir de una concepción estereotipada

\footnotetext{
${ }^{9}$ En este punto, es necesario precisar que las características sociolingüísticas (especialmente la formación cultural) de los autores del siglo XXI difieren notablemente de las que presentan los autores de siglos previos. Además, mientras que las cartas de los siglos XVIII y XIX son privadas e íntimas, las cartas del siglo XXI tienen una "privacidad fingida", ya que se sabe que van a ser leídas en un programa de telerrealidad ante sus espectadores.

${ }^{10}$ Las cartas de los siglos XIX y XX han sido extraídas de ediciones críticas de los epistolarios privados de cada uno de los remitentes. Las cartas del siglo XXI han sido recogidas y transcritas específicamente para la elaboración de este artículo a partir del capítulo 7 del programa 'La isla de las tentaciones', emitido el día 14 de octubre de 2020 en Telecinco.

${ }^{11}$ Los integrantes de cada pareja están divididos en dos villas diferentes, ubicadas en la República Dominicana: Villa Playa (chicas) y Villa Montaña (chicos). Durante un mes, convivirán con otros participantes solteros con el fin de consolidar sus relaciones.
} 
y prototípica de las categorías de los actos de habla ${ }^{12}$. Además, el rango de subtipos, enmarcados dentro de los actos directivos, es muy vasto: ruegos, sugerencias, consejos, advertencias, invitaciones, recomendaciones, etc. Aunque esta escala presenta evidentes diferencias internas, en función de la obligatoriedad del acto de habla, resulta complicado establecer límites precisos entre cada subtipo.

Para la presentación de las construcciones encontradas se sigue el modelo empleado por King (2012, p. 278) e Iglesias Recuero (2016, p. 975) $)^{13}$ : una clasificación basada en aspectos formales (tipos de enunciados y propiedades léxico-gramaticales de los mismos), considerando también la mayor o menor explicitud con que se formulan en el enunciado tanto el contenido de la petición como la referencia al encargado de llevarlo a cabo -el destinatario-. Además, para el análisis de cada construcción, se tienen en cuenta el tipo de relación de distancia, poder y solidaridad (Brown y Gilman, 1960) existente entre los interlocutores y, especialmente, el coste de lo solicitado (Leech, 2014).

Con el fin de seguir ahondando en la caracterización histórica del género epistolar, también estudiaremos los tratamientos y los mecanismos de apertura y cierre de las cartas, fórmulas fijadas y establecidas por la tratadística epistolar ${ }^{14}$ desde la época clásica. De esta forma se podrá observar cómo influyen los cambios sociales iniciados en el S.XIX en la configuración interna (estilo, tema, razones, conceptos, modos, términos, títulos, cortesías y tratamientos) de la correspondencia epistolar $^{15}$.

\section{La cortesía epistolar: datos globales y resultados}

Tabla 1. Datos globales del estudio ${ }^{16}$

\begin{tabular}{|c|c|c|c|c|c|c|c|c|c|c|c|c|}
\hline Construcciones & EPB & DA & S.XIX & $\%$ & PN & \% & M & H & S.XXI & \% & TOTAL & \% \\
\hline Desiderativas & 3 & 2 & 5 & $\mathbf{1 0 . 4 \%}$ & 0 & $\mathbf{0 \%}$ & 5 & 6 & 11 & $\mathbf{3 2 . 4 \%}$ & 16 & $\mathbf{1 3 . 8 \%}$ \\
\hline Volitivas & 0 & 3 & 3 & $\mathbf{6 . 2} \%$ & 4 & $\mathbf{1 1 . 8} \%$ & 3 & 3 & 6 & $\mathbf{1 7 . 7} \%$ & 13 & $\mathbf{1 1 . 2 \%}$ \\
\hline
\end{tabular}

\footnotetext{
${ }^{12}$ Uno de los problemas a los que se ha enfrentado la Pragmática histórica desde su origen es a la identificación de los actos directivos, puesto que su definición misma, su delimitación con respecto a otros actos, las condiciones de su uso y sus realizaciones lingüísticas pueden varias de una época a otra. Sin embargo, parece que las peticiones/órdenes son relativamente estables a lo largo del tiempo, como recoge en su estudio Iglesias Recuero (2016, p. 974).

${ }^{13}$ De esta forma evitamos realizar una clasificación basada exclusivamente en la naturaleza directa, indirecta convencional e indirecta no convencional de los actos de habla, ya que todavía no contamos con datos suficientes sobre el grado de pragmaticalización en estas etapas y son numerosas las divergencias surgidas al establecer las líneas divisorias entre lo directo y lo indirecto convencional, y lo indirecto convencional y no convencional.

${ }^{14}$ Los manuales de cartas, también denominados formularios, tratados o secretarios, son textos que presentan una teoría sobre los usos correctos a la hora de escribir cartas, en función de la preceptiva epistolar de cada momento histórico. Durante la Edad Moderna, la configuración de una auténtica civilización epistolar provocó que proliferasen este tipo de obras, las cuales mostraban siempre una gran preocupación por los tratamientos y cortesías que debían emplearse en las cartas.

${ }^{15}$ Por las limitaciones de espacio, no podemos entrar en una discusión sobre la evolución externa de la carta (formato, materialidad del papel, disposición de la escritura y tipo de letra) que, evidentemente, también se ha visto afectada por los cambios sociohistóricos.

16 Todas las tablas han sido elaboradas por la autora. Las construcciones que aparecen en la tabla se analizan detalladamente en las siguientes páginas.
} 


\begin{tabular}{|c|c|c|c|c|c|c|c|c|c|c|c|c|}
\hline Imperativo / Subj. & 15 & 8 & 23 & $47.9 \%$ & 17 & $50 \%$ & 3 & 1 & 4 & $11.8 \%$ & 44 & $38 \%$ \\
\hline $\mathrm{Vb}$ realizativo & 1 & 0 & 1 & $2.1 \%$ & 0 & $0 \%$ & 0 & 0 & 0 & $\mathbf{0 \%}$ & 1 & $0.9 \%$ \\
\hline Deber + infinitivo & 0 & 1 & 1 & $2.1 \%$ & 2 & $5.9 \%$ & 0 & 0 & 0 & $0 \%$ & 3 & $2.6 \%$ \\
\hline Es necesario que & 1 & 0 & 1 & $2.1 \%$ & 0 & $0 \%$ & 0 & 0 & 0 & $0 \%$ & 1 & $0.9 \%$ \\
\hline Poder + verbo & 0 & 0 & 0 & $0 \%$ & 2 & $5.9 \%$ & 0 & 1 & 1 & $2.8 \%$ & 3 & $2.6 \%$ \\
\hline $1^{\mathrm{a}} \mathrm{p}$. del plural & 3 & 0 & 3 & $6.3 \%$ & 4 & $11.8 \%$ & 1 & 2 & 3 & $8.8 \%$ & 10 & $8.6 \%$ \\
\hline $3^{\mathrm{a}} \mathrm{p}$. del singular & 0 & 4 & 4 & $8.3 \%$ & 0 & $0 \%$ & 0 & 0 & 0 & $0 \%$ & 4 & $3.4 \%$ \\
\hline $\begin{array}{c}\text { Condicional, futuro, } \\
\text { pregunta }\end{array}$ & 4 & 1 & 5 & $10.4 \%$ & 4 & $11.8 \%$ & 1 & 2 & 3 & $8.8 \%$ & 12 & $10.3 \%$ \\
\hline Disculpa & 2 & 0 & 2 & $4.2 \%$ & 0 & $0 \%$ & 0 & 2 & 2 & $5.9 \%$ & 4 & $3.4 \%$ \\
\hline Tú sabes... & 0 & 0 & 0 & $0 \%$ & 1 & $2.8 \%$ & 3 & 1 & 4 & $11.8 \%$ & 5 & $4.3 \%$ \\
\hline TODAS & 29 & 19 & 48 & $100 \%$ & 34 & $100 \%$ & 18 & 18 & 34 & $100 \%$ & 116 & $100 \%$ \\
\hline
\end{tabular}

El catálogo de construcciones empleadas constata un predominio del uso del enunciado imperativo (o subjuntivo en los casos de enunciados negativos) durante los siglos XIX y XX. En ambos siglos esta forma directa de realización supera el $47 \%$ de las construcciones empleadas. Sin embargo, durante el siglo XXI observamos un cambio de tendencia pues las aserciones desiderativas $(32.4 \%)$ y volitivas $(17.7 \%)$ pasan a ser las construcciones más usadas.

A continuación analizaremos los distintos tipos de construcciones encontradas.

\subsection{Enunciados en imperativo o subjuntivo}

Los enunciados en imperativo o en subjuntivo, para las oraciones negativas, son los más empleados en las cartas de los siglos XIX y XX. En estas cartas, la situación de familiaridad y el grado de afecto existente entre los interlocutores habilita el uso de estas construcciones directas, minimizando el grado de imposición en el destinatario:

1) Perdóname el agravio y el error, porque he visto que te hice mucho daño (Emilia Pardo Bazán a Benito Pérez Galdós).

2) No me lleves a mal nada de lo que en esta carta te escribo (Emilia Pardo Bazán a Benito Pérez Galdós).

3) No olvides tu promesa, viejo. Sé juiciosito. Pensá que tenés una hijita y que debes cuidarte para ella (Delmira Agustini a Enrique Job).

4) No me dudes nunca, mi vida nunca!... Duda de todos del mundo, de la Vida, de todo! (Delmira Agustini a Enrique Job).

5) Ahora no me escribas más privadamente. Contéstame en forma general sobre tu vida y proyectos (Pablo Neruda a Matilde Urrutia).

6) Te quiero mi amor, no seas perra, espérame (Pablo Neruda a Matilde Urrutia).

Aunque en las cartas del siglo XXI no son las construcciones predominantes, también encontramos enunciados en imperativo, siguiendo el mismo patrón que las presentadas anteriormente (relación simétrica de proximidad, familiaridad y afecto): 
7) Te quiero mi amor, no seas perra, espérame (Pablo Neruda a Matilde Urrutia).

8) Disfruta mucho la experiencia, pero con mucha cabeza (Mayka a Pablo).

9) Se tú al 100 x 100 y créeme que te estaré esperando al final de esa última hoguera (Patricia a Alessandro).

Esta evolución parece apuntar a una concepción distinta del valor social e interpersonal de esta forma verbal a lo largo de la historia, como ya señaló Iglesias Recuero (2016, p. 978) en su investigación del español áureo, etapa donde se constata un predominio casi absoluto del imperativo (supone algo más del $80 \%$ de los 354 actos directivos analizados). Si bien las condiciones entre los interlocutores son prácticamente idénticas en los tres siglos estudiados -situación de extrema familiaridad, posición social equitativa y coste de las peticiones equiparable-, se produce un descenso notable en el uso del imperativo en las peticiones: del $47.9 \%$ del siglo XIX y 50\% del siglo XX al $11.8 \%$ del siglo XXI.

Actualmente, el imperativo se considera la forma más directa de expresión de un acto directivo, por lo que también constituye la forma más descortés, reservada a situaciones muy excepcionales y con unas características concretas: proximidad absoluta entre los interlocutores, coste mínimo para el destinatario o situación de emergencia (Brown y Levinson, 1987). En el caso de que no se diesen estas condiciones, los hablantes optan por formulaciones menos impositivas y más indirectas, como las volitivas o las interrogaciones, que reflejan el deseo del emisor de dar más libertad de acción a su interlocutor.

\subsection{Expresiones realizativas}

Las expresiones realizativas son, junto al imperativo, las expresiones más directas y menos corteses del español actual. Al igual que ocurría con los enunciados en imperativo, su uso está muy restringido, por eso los hablantes optan por emplear otras expresiones menos directas y explícitas. Esto explica su mínima presencia en las cartas estudiadas, representando tan solo el $0.9 \%$ de los actos directivos.

En nuestro corpus únicamente hemos encontrado un enunciado construido con verbo en forma realizativa:

10) Por la tarde podré desahogar un poco el corazón rogándote que no pierdas enteramente el cariño a la que te lo profesa santo y eterno (Emilia Pardo Bazán a Benito Pérez Galdós).

En este ejemplo, se emplea rogar, uno de los verbos más deferenciales junto a suplicar. Este verbo expresa abiertamente que el hablante se sitúa en una posición de inferioridad con respecto al destinatario. En este caso concreto, la deferencialidad no se explica por causas sociales (estatus inferior), sino por el peso (coste) de la petición, ya que Emilia Pardo Bazán pide en esta carta a Benito Pérez Galdós que la perdone por haberle sido infiel.

Emilia Pardo Bazán, consciente de haber transgredido las normas habituales de comportamiento en su relación sentimental, emplea el verbo rogar como una estrategia de retórica persuasiva vinculada al contenido de su petición. 


\subsection{Aserciones volitivas y desiderativas}

Las aserciones volitivas y desiderativas son las segundas construcciones más empleadas en el corpus, constituyendo entre las dos el $25 \%$ del total. Ambas siguen el mismo patrón estructural: verbo (esperar -16 casos- o querer -13 casos-) en primera persona del singular en presente de indicativo y oración subordinada completiva de objeto. A través de este tipo de construcciones el hablante expresa abiertamente su deseo de que el destinatario realice la acción descrita en la subordinada.

11) Espero que te lo estes pasando genial y vivas al máximo esta experiencia. Ojalá y esto nos sirva a ambos para poder solucionar todos los problemas que pudiésemos tener (Pablo a Mayka).

12) Espero que te acuerdes mucho de mí y me tengas presente, aunque no esté ahí (Mayka a Pablo).

13) Espero que me estes echando de menos y que cuando todo esto acabe podamos decir que somos más fuertes que nunca y que todo esto quede en una adegdota. [...] Espero que todo esto te sirva para que sientes por completo la cabeza y demostremos a todo el mundo que todo lo que emos pasado ha merecido la pena (Melodie a Christian).

14) Espero que se repitan aquellas escenas deliciosas (Emilia Pardo Bazán a Benito Pérez Galdós).

15) Yo quiero desvanecer esa mala sombra de un momento, yo no quiero que reaparezca en tu alma ni en tus ojos porque a mi también me hiere (Delmira Agustini a Enrique Job).

16) Quiero salir de aquí fortalecida, pero fortalecida contigo y seguir creando nuestra vida juntos (Patricia a Alessandro).

17) Quiero estar contigo el resto de mi vida, tener hijos, hacernos viejos juntos, disfrutar de cada minuto a tu lado y bebernos toda la vida (Marta a Lester).

18) Quiero saberlo todo, y lo averiguaré en todo caso (Pablo Neruda a Matilde Urrutia).

La tendencia evolutiva de las estas aserciones es inversa a la de los enunciados en imperativo ya que su uso se incrementa exponencialmente con el paso de los siglos: del 16.6\% del siglo XIX al 50.1\% del siglo XXI. Su aparición en el siglo XX es todavía inferior, pues tan solo supone el 11.8\% de las construcciones empleadas en ese arco temporal.

Aunque la clasificación de estas construcciones difiere según los autores ${ }^{17}$, existe un punto en común, pues siempre son situadas en un grado inferior de imposición respecto a las construcciones imperativas y realizativas. De hecho, para Hakerkate (1994) ocuparían el segundo lugar en su escala, inmediatamente después de los enunciados con imperativo y con verbo realizativo. Lo que diferencia a estos dos tipos construcciones ilocutivas no es tanto la intención del hablante, sino el grado de mitigación de la imposición. En ambos casos el hablante intenta lograr que

${ }^{17}$ Mientras Brum-Kulka et al. (1989) las incluyen dentro del grupo de expresiones directas, Leech (2014) las considera expresiones indirectas explícitas. 
el destinatario lleve a cabo una acción, lo que se modifica es la forma lingüística de expresarlo. Al incluir verbos como querer o esperar se suaviza la asertividad, se reduce notablemente su naturaleza impositiva $\mathrm{y}$, por ende, se aproxima a las denominadas actualmente estrategias corteses.

La aparición de este tipo de construcciones en nuestro corpus constata, de nuevo, la preferencia actual por estrategias menos directas para una misma situación comunicativa y la distinta atribución de valores de cortesía a las formas lingüísticas (in)directas con el transcurso del tiempo.

\subsection{Aserciones deónticas}

En nuestro corpus contamos con 4 enunciados formados por aseveraciones de modalidad deóntica, lo que supone el 3.5\% del total de actos analizados. Dentro de ellos distinguimos dos tipos de construcciones: las formadas por el verbo modal deber y los predicados impersonales como es necesario. Ninguno de estos enunciados se halla en las cartas del siglo XXI, atestiguando la preferencia actual por la indirección.

La perífrasis de modalidad deóntica deber + infinitivo es empleada en 3 ocasiones en cartas de los siglos XIX y XX. No se ha documentado ningún ejemplo en las cartas del siglo XXI. En todas ellas el beneficiario principal de la acción es el emisor:

19) Pensá que tenés una hijita y que debes cuidarte para ella (Delmira Agustini a Enrique Job).

20) Debes hacer lo que te pido (Pablo Neruda a Matilde Urrutia).

21) Debes preparar tu viaje, pero con calma, como cuando comemos (Pablo Neruda a Matilde Urrutia).

En ambas situaciones comunicativas, no existe una jerarquía social marcada entre los interlocutores, por lo que esta perífrasis no es una orden clara, sino que es subjetiva. En estos ejemplos, el emisor se sitúa en una posición autorizada para expresar la necesidad de realizar un acto determinado: cuidarse, hacer lo que le pide o preparar un viaje, respectivamente. En el último ejemplo, se mitiga su naturaleza impositiva a través de la expresión adversativa 'pero con calma'.

En el corpus también encontramos una construcción impersonal deóntica con el predicado es necesario que:

22) Es necesario que nos veamos (Emilia Pardo Bazán a Benito Pérez Galdós).

Este tipo de enunciado presenta como necesaria una acción futura del destinatario, explicitada en la subordinada. En este ejemplo particular, la urgencia de la situación comunicativa -Emilia Pardo Bazán desea reencontrarse con Benito Pérez Galdós ante el retraso de su viaje en tren- habilita el empleo de esta construcción deóntica.

\subsection{Construcciones con mayor grado de indirección}

A lo largo del corpus se han encontrado también enunciados que presentan un grado mayor de indirección, aunque mantienen su interpretación como directivos: 
enunciados con futuro, enunciados interrogativos, condicionales ilocutivas, perífrasis epistémicas o enunciados con saber.

En total, estas construcciones suponen el $17.2 \%$ de los actos directivos del corpus. Al igual que ocurría con las aserciones volitivas y desiderativas, se constata un incremento progresivo del uso de este tipo de enunciados: en el siglo XIX tan solo suponen un $10.4 \%$ de las construcciones empleadas, en el siglo XX ya suponen un $20.5 \%$ del total y, finalmente, en las cartas del siglo XXI constituyen un $23.5 \%$ del total. Solo las aserciones volitivas y desiderativas aparecen en más ocasiones que estas construcciones indirectas en el siglo XXI. Mientras que en los siglos precedentes, como ya se ha mencionado anteriormente, existe un predominio casi absoluto de las formas explicitas de realización de la petición -enunciados en imperativo o subjuntivo-.

Evidentemente, dentro de esta subcategoría existen diferencias escalares en función tanto del grado de imposición del hablante como del grado de inferencia que es necesario realizar para el reconocimiento de la fuerza ilocutiva directiva del enunciado (Blum-Kulka et al., 1989, p. 18-20).

En primer lugar, se situarían los enunciados con una forma de futuro en $2 .^{\mathrm{a}}$ persona. En estos casos, el objetivo sigue siendo influir en el comportamiento intencional del interlocutor. El beneficio vuelve a recaer en el emisor, quien se siente con derecho a pedir a su destinatario que haga una determinada acción:

23) Tu decidirás (Pablo Neruda a Matilde Urrutia).

Inmediatamente después, se localizarían las construcciones condicionales con valor directivo. Las condicionales documentadas en nuestro corpus son empleadas con el fin de instigar al destinatario a que lleve a cabo la acción de la apódosis.

24) Si me retraso, espérame (Emilia Pardo Bazán a Benito Pérez Galdós).

25) Si vienes cuenta conmigo para que se me quite la rabia (Pablo Neruda a Matilde Urrutia).

En algunos casos, la prótasis adopta la forma de una condicional de cortesía, apelando a la disposición del interlocutor de llevarla o no a cabo, por lo que son una especie de 'orden encubierta':

26) Si quieres enviarme algo que me guste, envía pliegos de Realidad (Emilia Pardo Bazán a Benito Pérez Galdós).

Numerosos autores, como Brown y Levinson (1987) o Leech (2014), han catalogado las peticiones formuladas mediante interrogaciones como enunciados corteses, pues esta forma lingüística explicita la opcionalidad del destinatario para cumplir lo solicitado:

27) No podrías venir a París? (Pablo Neruda a Matilde Urrutia).

28) Pero no, mi amor, tú comprendes, verdad los celitos, locos de tu Nena? (Delmira Agustini a Enrique Job). 
En nuestro corpus, estos tres tipos de enunciados se documentan en las cartas de los siglos XIX y XX. No soy expresiones muy frecuentes en la época estudiada, pero sí lo son en el español actual, aunque, curiosamente no se han encontrado ejemplos en las cartas que conforman nuestro corpus.

Las construcciones indirectas más empleadas en las cartas del siglo XXI son los enunciados constituidos por la perífrasis epistémica poder + infinitivo y los que presentan al destinatario como conocedor de las causas que provocan la petición (tú sabes que + oración subordinada). En ambos casos se disimula el atrevimiento que supone la petición pero existen diferencias entre las construcciones.

La perífrasis poder + infinitivo $^{18}$ aminora la instrucción, alejando el sentido de la exigencia y dejando constancia de las posibilidades de acción del destinatario:

29) Puedes estar tranquila y confiar en mí (Lester a Marta).

30) Puedes escribir a Miguel Otero Silva (Pablo Neruda a Matilde Urrutia).

Mientras que, en el segundo tipo de construcción, la petición se convierte en lícita al presentar al destinatario como conocedor de las causas:

31) Tu sabes que no soy la persona más detallista del mundo pero soy seguro la que más te quiere aunque no te lo diga todos los días y lo grite al viento (Lester a Marta).

32) Sabes que te voy a echar tantísimo de menos, que eres lo más importante que tengo en mi vida (Patricia a Alessandro).

33) Ya sabes que cuando acabe esto aquí estaré esperándote (Mayka a Pablo).

En un ejemplo del siglo XX, esta construcción se convierte en reproche, pues se incrementa la imposición, se intensifica el ataque a la imagen del destinatario y se espera una respuesta diferente a la recibida previamente:

34) No sabes qué furia tuve cuando el mismo día que llegamos te llamo y no contestas (Pablo Neruda a Matilde Urrutia).

A través de estas cinco estructuras lingüísticas no solo se justifica la petición sino que se refuerza la imagen positiva del emisor al no agredir la imagen negativa del destinatario. Una retórica de la cortesía, que ya se atisba en el siglo XIX y consolidada en nuestros días, a través de la cual el hablante busca, principalmente, trabajar su propia imagen (Albelda, 2013, p. 332-334).

\subsection{Despersonalización de la petición}

La elección de la persona en cada forma formal también constituye un mecanismo atenuador del acto directivo, al presentar la solicitud como necesaria pero, a la vez, ajena a la voluntad del emisor e involucrando explícitamente a su destinatario.

En nuestro corpus se observan dos tipos de procedimientos morfológicos que responden a este tipo de atenuación despersonalizada:

\footnotetext{
${ }^{18}$ En las cartas del siglo XIX no se documenta ninguna muestra de esta construcción.
} 
- Empleo de la primera persona del plural (nosotros), que sitúa al emisor y al destinatario al mismo nivel de responsabilidad de lo enunciado, aunque el fin último sea lograr que el interlocutor realice la acción. Este tipo de despersonalización se documenta en un total de 10 casos $(8.6 \%$ del total de construcciones), de forma equitativa entre los tres siglos estudiados:

35) No quedemos mal por un cochino libro más o menos (Emilia Pardo Bazán a Benito Pérez Galdós).

36) Todo esto, con gran esfuerzo lo hablaremos (Pablo Neruda a Matilde Urrutia).

37) Nos vemos pronto (Pablo a Mayka).

38) Nuestro comienzo de relación sabemos que ha sido complicado (Alessandro a Patricia).

- Empleo de la tercera persona del singular para dirigirse al destinatario, en lugar de recurrir a la segunda persona del singular. Este procedimiento es exclusivo del discurso de Delmira Agustini, quien usa la tercera persona tanto para dirigirse a Enrique Job como para hablar de ella misma -se autorefiere como 'la Nena'-. Parece que esta construcción forma parte de la retórica personal de Delmira. Es posible que a través de su empleo intente aminorar el carácter de obligación de lo solicitado pues recurre a esta estructura al tratar su obsesión por los celos:

39) Nunca tendrá la Nena motivo de celos (Delmira Agustini a Enrique Job).

40) Pero él quiere mucho a la Nena y se va a portar buenito porque si no ella se muere de tristeza (Delmira Agustini a Enrique Job).

\subsection{Disculpas}

Aunque las disculpas no son actos directivos, se han incluido en el análisis como elementos de apoyo de la (des)cortesía. Haverkate (1994, p. 97) las define como un acto de habla expresivo cuyo objetivo ilocutivo es dar a conocer al interlocutor que se ha violado cierta norma social y que él, es decir, el hablante, se cree responsable de haber ocasionado dicha violación.

A diferencia de los actos directivos, la disculpa supone un beneficio para el destinatario y un coste para el emisor y, por tanto, intentan mantener o mejorar la relación social existente entre ellos. Las disculpas apuntan a restaurar el equilibrio o, al menos, a reducir el desequilibrio entre hablante y oyente, creado por una acción anterior de uno de ellos. Desde esta perspectiva, la disculpa es perfectamente comparable al agradecimiento: ambos son actos expresivos reactivos.

Sin embargo, si precisamos en este ámbito, vemos como el emisor también recibe un beneficio (mejora su imagen personal al realizar la disculpa) y la relación entre emisor y destinatario puede deteriorarse si se rechaza la disculpa. Esto otorgaría ambigüedad a las disculpas, puesto que aparentemente son acciones que apoyan a la cortesía pero también se pueden catalogar como acciones que entran en conflicto con la cortesía y deben ser compensadas.

En las cartas de nuestro corpus se han contabilizado 4 disculpas, en las cuales el emisor muestra su arrepentimiento por un hecho anterior. Estos actos, al situar al 
emisor en una posición de inferioridad, facilitan la introducción de actos directivos, disimulando su imposición:

41) Perdón si me he portado mal y te he hecho sufrir (Christian a Melodie).

42) Si no te habia apoyado es por que verte sufrir me ha dolido muchísimo (Tom a Melyssa).

43) Perdona mi brutal franqueza [...] Perdóname el agravio y el error (Emilia Pardo Bazán a Galdós).

\section{Estructura epistolar: mecanismos de apertura y cierre y tratamientos}

Si algo caracteriza al género epistolar es su estabilidad estructural a lo largo de los siglos. La estructura epistolar, fijada ya en los primeros tratados del mundo clásico ${ }^{19}$ y de manera más clara en las epístolas ciceronianas, ha permanecido casi inmóvil hasta nuestros días. Este patrón textual se articula en torno a tres partes fundamentales -proemio, discurso y fin (Castillo Gómez, 2014, p.35)- que se observan con facilidad en las cartas de nuestro estudio. Resulta paradójico que, a pesar de la aparente simplicidad del objeto, desde la Antigüedad Clásica se haya elaborado una sustanciosa teoría epistolar que ha ido modelando las características de las diferentes tipologías de cartas.

Durante la Ilustración, el rígido estilo epistolar cortesano fue paulatinamente sustituido por un nuevo modo de escribir cartas, mucho más simple y menos sobrecargado, acorde con las características de la lengua y sociedad dieciochescas. Este rechazo a la retórica clásica epistolar se evidencia en las crecientes críticas al uso obsoleto de la cortesía, especialmente a los formulismos honoríficos de la apertura y al besalamanos del cierre epistolar ${ }^{20}$, fórmulas que fueron sustituidas por otras más apropiadas al momento histórico. La modernización del paradigma epistolar español culminó en el siglo XIX, con los manuales de Marqués Espejo (1803), Sas (1819) y Pellicer (1832), que apuestan abiertamente por un nuevo estilo, alejado del arcaizante modelo barroco. Precisamente este último manual, el Secretario español de Pellicer, ha sido considerado por Sáez Rivera (2015) precursor de la teoría pragmática clásica (Brown y Gilman, 1960; Brown y Levinson, 1978) por las modernas ideas sobre cortesía y formas de tratamientos que presenta. La sociedad ilustrada, alejada de la marcada estratificación social previa, inauguró un nuevo modelo de escribir cartas.

\footnotetext{
${ }^{19}$ Según se establece en la retórica clásica, las partes básicas de una carta eran las siguientes: Salutatio: compuesta por la expresión inicial de saludo y, en su caso, por la invocación precedente en forma de cruz.

Captatio benevolentiae o expressio malevolentiae: esta fórmula servía para introducir el texto aludiendo a la relación con las cartas anteriores o a la ausencia de éstas, seguida de las expresiones de deseo concernientes a la salud del que escribe, su corresponsal y los respectivos círculos afectivos. Narratio: el cuerpo del texto.

Petitio o captatio benevolentiae: fórmula final con la que el remitente corrobora sus buenos deseos hacia su corresponsal, familiares y amigos.

Conclusio: integrada por la data, la consiguiente expresión de humildad o sumisión y la suscripción autógrafa.

${ }^{20}$ Las fórmulas de apertura y cierre de las cartas, surgidas en la época feudal, se habían lexicalizado, por lo que resultaban totalmente inapropiadas para el siglo XVIII y su actualización era necesaria.
} 
Las cartas que conforman este corpus reflejan esa mayor libertad en las formas de saludo y despedida y constatan un relajamiento en las cortesías epistolares, que tan severas habían sido en los siglos previos. Los saludos contienen apelativos cariñosos (amor mio, mi Quique, miquiño), referencias temporales (fecha) y fórmulas de apertura (hola - empleada exclusivamente en el siglo XXI). Por su parte, las despedidas incluyen expresiones amorosas (te quiero, te amo, besos, siempre juntos), apelativos cariñosos (tu Nena, tu Porcia, tu muñeca, tu capitano) y referencias temporales (hasta luego, hasta pronto, buen día, buena noche). Todas estos mecanismos de inicio-cierre de conversación se emplean actualmente, tanto en la comunicación escrita como en la oral.

En cuanto a los tratamientos, el pronombre empleado mayoritariamente es tú. Tan solo encontramos una muestra de vos en las cartas de Delmira Agustini, pronombre de familiaridad en la variedad rioplatense, y otra de usted ${ }^{21}$ en las de Pablo Neruda. El predominio de tú es totalmente esperable al tratarse de cartas entre parejas sentimentales, pues su uso como pronombre de proximidad y familiaridad estaba ya extendido y consolidado.

Un punto que señalar en los tratamientos de nuestro corpus es la presencia de los posesivos. Estas construcciones expresan y remarcan el tipo de relación existente entre los interlocutores. Si bien en todos los siglos encontramos apelativos conformados por posesivos, del tipo mi novia, mi amor, mi muñeca, mi + nombre de pila/diminutivo, su frecuencia de aparición es decreciente con el paso del tiempo. Las siguientes gráficas explicitan esta evolución:

Gráfico 1. Datos globales del uso de los posesivos.

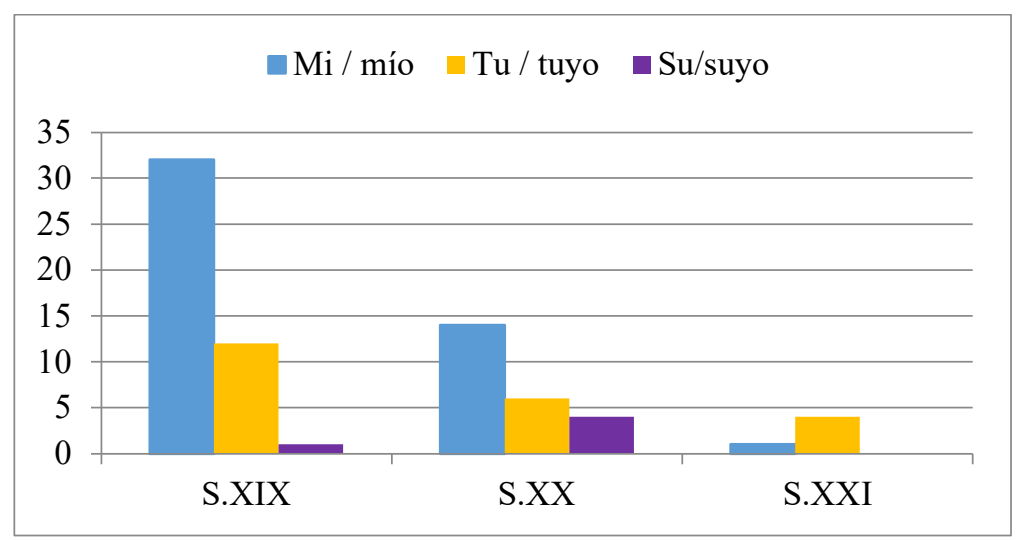

${ }^{21}$ Pablo Neruda no usa en una carta usted exclusivamente, sino que intercala el uso de tú a lo largo del texto. 
Gráfico 2. Datos particulares del uso de los posesivos.

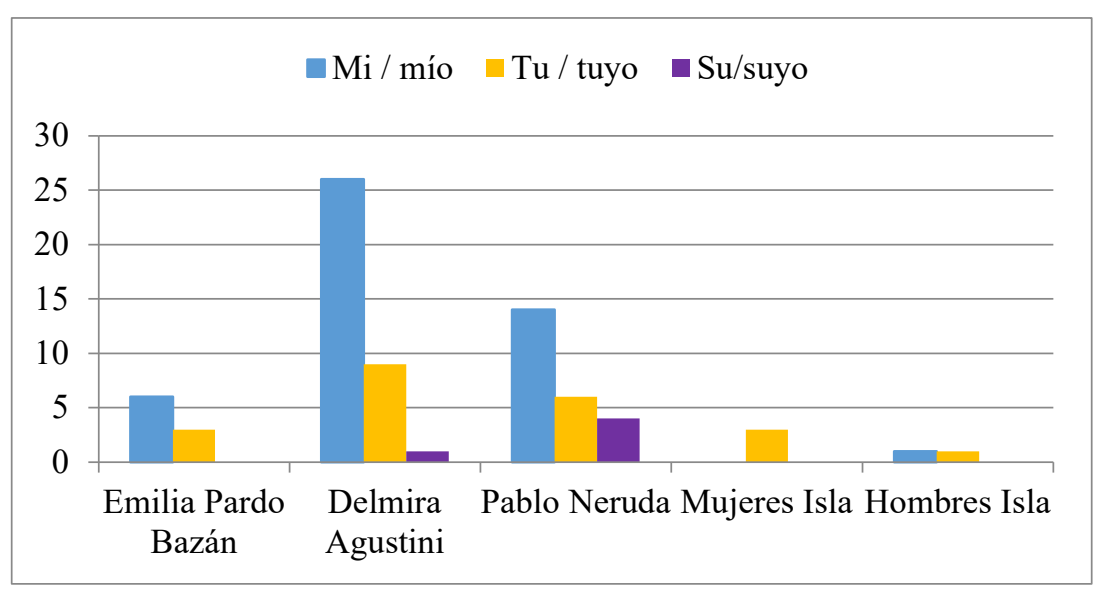

Llama especialmente la atención el uso de los posesivos en las cartas de Delmira Agustini, quien recurre constantemente a ellos para dirigirse a su esposo: tu nena, mi vida, mi Quique, mi Enrique o mi amor. De hecho, cierra varias de sus cartas con la expresión 'tuya, tuya' o 'tuya mucho, mucho, mucho'.

\section{Conclusiones}

Después de esta somera descripción de las construcciones empleadas en la formulación de peticiones en nuestro restringido corpus epistolar, destacan dos aspectos: en primer lugar, como muestran las tablas 4 y 5 , el descenso progresivo del predominio de expresiones directas, especialmente del imperativo, en favor de expresiones indirectas convencionales como las aserciones volitivas y desiderativas o las interrogaciones con poder; en segundo lugar, la estabilidad estructural del género epistolar, manteniendo visible su patrón textual (cabeza, cuerpo y fin).

Gráfico 3. Datos por autor de las construcciones documentadas en el corpus.

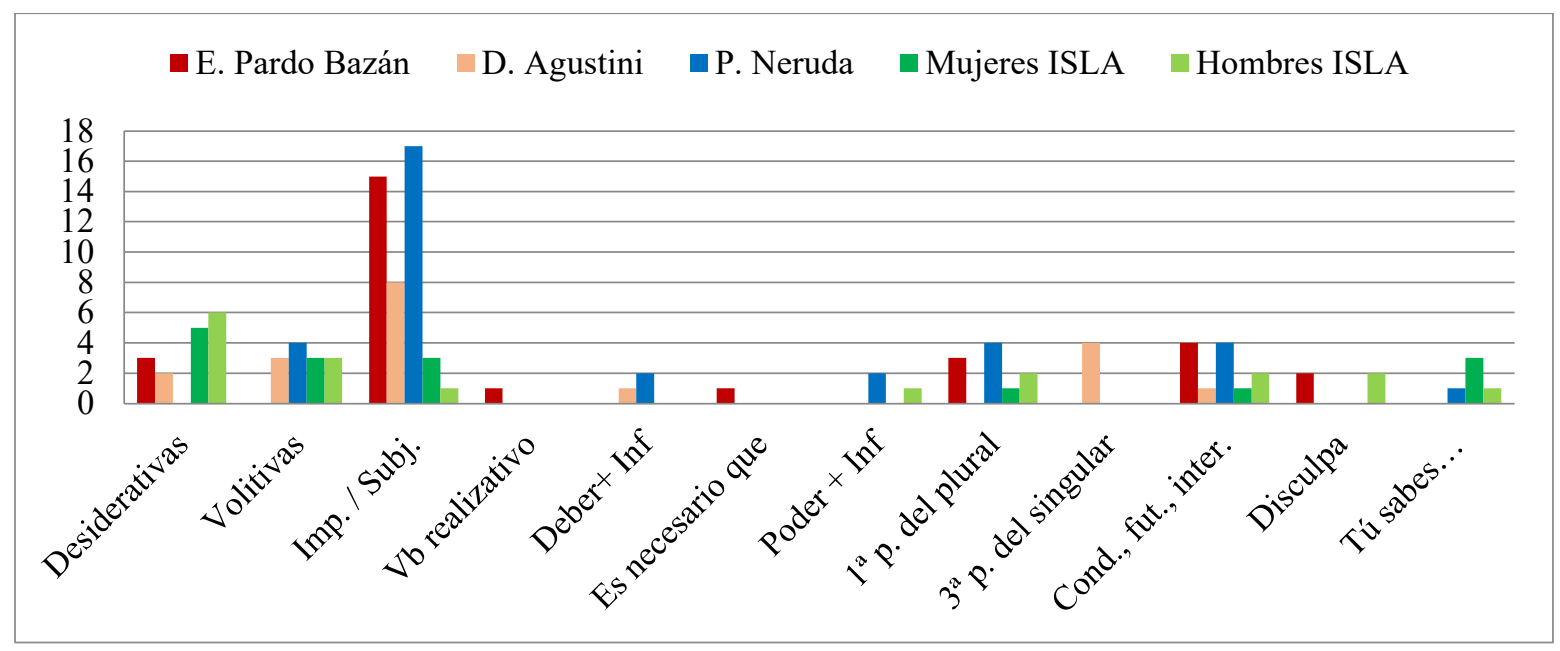


Gráfico 4. Datos globales de las construcciones documentadas en el corpus.

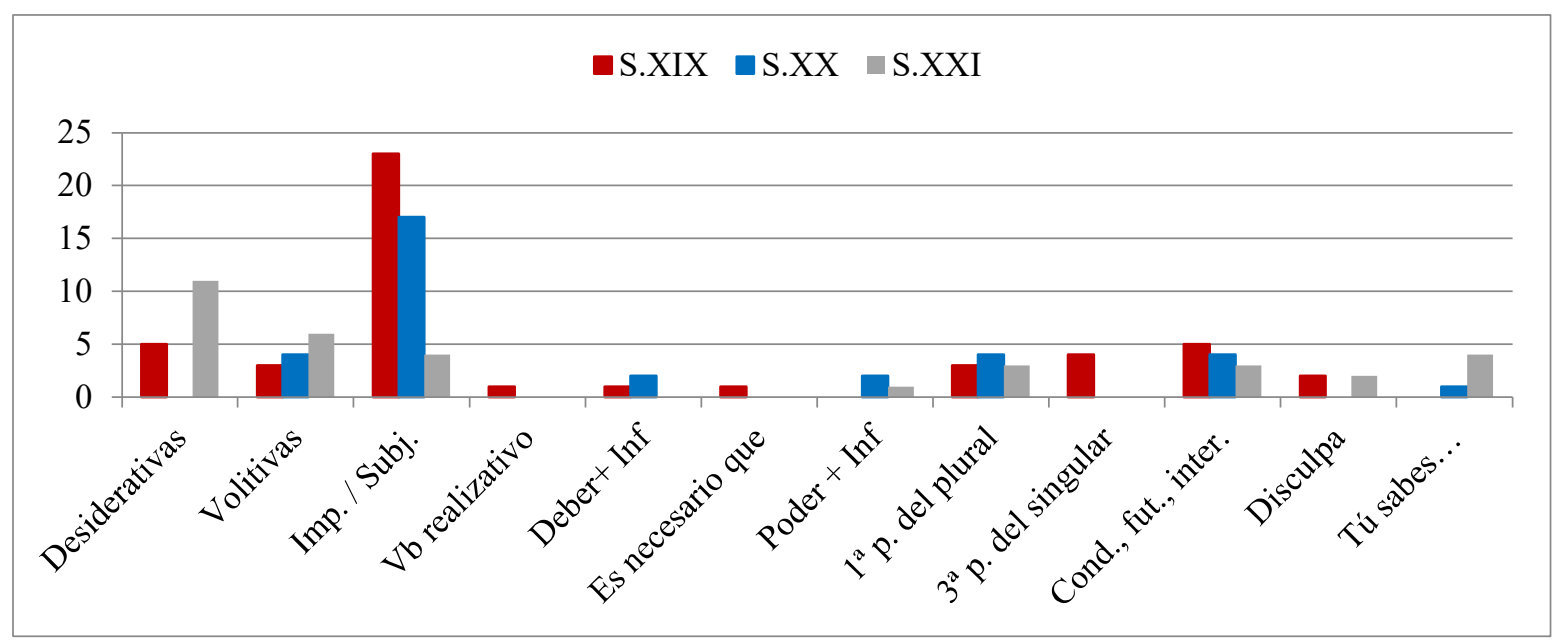

El primer resultado parece apuntar a una distinta concepción en los siglos pasados de las construcciones explícitas, tanto del imperativo como de los enunciados con verbos realizativos. No es que las remitentes del siglo XIX fuesen más descorteses que los de la actualidad por emplear el imperativo, es que atribuían distintos valores de (des)cortesía a las estrategias lingüísticas.

Con respecto al segundo resultado, estas cartas reflejan la flexibilización de las formalidades barrocas a partir de la Ilustración. Gradualmente, el movimiento de alfabetización ilustrado convirtió el uso de la carta en un hábito social, incluso para individuos de clase media-baja. En este contexto sociocultural, es natural que surgiese y se afianzase un modo de escribir más simple que el del pasado. Sin embargo, la despreocupación por el que estaba al otro lado del papel ha perdurado durante toda la tradición epistolar: la elección de los tratamientos ha continuado realizándose en función del asunto de la carta y de la relación (simétrica-asimétrica) con el destinatario. En suma, la cortesía epistolar se ha ido modificando y adaptando en función de los usos y costumbres sociales de cada momento: del rigor y protocolo barroco a la popularización ilustrada de los tratamientos.

Este trabajo pretende ser una aportación a los estudios de la pragmática histórica del español. Los resultados expuestos se corresponden únicamente con las cartas que componen este corpus de estudio, por lo que no son suficientes para generalizar sobre el uso de los actos directivos en un rango temporal tan amplio (siglos XVIII-XIX). Como recoge Iglesias Recuero (2016, p. 991), solo estudios más amplios, que abarquen otros géneros discursivos e incluyan más variedades diastráticas y diafásicas, ayudarán a aquilatar la validez de las observaciones aquí realizadas, a completar el catálogo de formas que tenían a su disposición los hablantes de otras épocas y a describir las condiciones de uso que favorecían el empleo de unas u otras.

\section{Referencias}

\section{Referencias primarias}

1. Agustini, D. (2005), Cartas de amor y otra correspondencia íntima. Prólogo de Idea Vilariño. Montevideo: Editorial Cal y Canto. 
2. Neruda, P. (2010), Cartas a Matilde Urrutia (1950-1973). Edición, introducción y notas de Darío Oses. Barcelona: Seix Barral.

3. Pardo Bazán, E. (2013 [1883-1915]), "Miquiño mio". Cartas a Galdós. Edición de Isabel Parreño y Juan Manuel Hernández. Madrid: Turner.

\section{Referencias secundarias}

1. Albelda, M. (2013): La atenuación: tipos y estrategias. En Gómez Molina, J. A. (Coord.), El español de Valencia. Estudio sociolingüístico (pp. 315-343). Frankfurt am Main: Peter Lang.

2. Albitre Lamata, P. (2020): El género epistolar y la (des)cortesía histórica: estado de la cuestión y reflexión crítica. Textos en proceso, 6(1), pp. 118-145. DOI: https://doi.org/10.17710/tep.2020.6.1.7albitre

3. Albitre Lamata, P. (2019): Análisis de los mecanismos de cortesía en cartas españolas del S.XVI. Revista de Filología y Lingüistica de la Universidad de Costa Rica, 45(2), pp. 27-66. DOI: https://doi.org/10.15517/rfl.v45i2.39113

4. Bello Hernández, I. (2019): La cortesía en Canarias a finales del siglo XVIII y principios del XIX: saludos, despedidas y formas de tratamiento en un corpus de cartas. Trabajo final de máster inédito, Universidad Complutense de Madrid.

5. Blas Arroyo, J. L. (Dir.), Porcar Miralles, M., Velando Casanova, M. y Vellón Lahoz, J. (2019): Sociolingüística histórica del español. Tras las huellas de la variación y el cambio lingüistico a través de textos de inmediatez comunicativa. Madrid/Frankfurt am Main: Iberoamericana/Vervuert.

6. Blum-Kulka, S., J. House, y G. Kasper (Eds.) (1989a): Cross-Cultural Pragmatics: Requests and Apologies. Norwood: Ablex.

7. Brenes Peña, E, Fuentes Rodríguez, C. y González Sanz, M. (Coords.) (2020): (Des)cortesía, actividades de imagen e identidad. Sevilla: Universidad de Sevilla, Colección Lingüistica. DOI: https://doi.org/10.12795/9788447230211

8. Brown, P. y Levinson, S. (1987 [1978]): Politeness. Some Universals in Language Usage. Cambridge: Cambridge University Press. DOI:

https://doi.org/10.1017/CBO9780511813085

9. Brown, R. y Gilman, A. (1960): The Pronouns of Power and Solidarity. En Sebeok, T. A. (ed.), Style in Language, (pp. 253-276). Cambridge: MIT Press. Caffi/Janney.

10. Bustos Gisbert, E. (2007): La expresión de la cortesía en Bernal Díaz del Castillo. En puigvert Ocal, A. y Delgado cobos, I. (Coords.), Ex admiratione et amicitia. Homenaje a Ramón Santiago (pp. 159-178). Madrid: Ediciones del Orto.

11. Bustos Gisbert, E. e Iglesias Recuero, S. (2003): Relaciones familiares y formas de tratamiento en la novela realista del siglo XIX. En Girón Alconchel, J. L. et al. (Coords.), Estudios ofrecidos al profesor José Jesús de Bustos Tovar (Vol. 1, pp. 277-296). Madrid: Editorial Complutense.

12. Cano Aguilar, R. (1995): Pragmática lingüística e historia de la lengua. Cauce: Revista Internacional de Filología, Comunicación y sus Didácticas, 18-19, pp. 703718.

13. Carrera de la Red, M. (2013): Análisis del discurso y sociopragmática histórica en un debate legal en la Cartagena de Indias del siglo XVIII. Intensificación y atenuación como recursos argumentales. Pragmática Sociocultural/Sociocultural Pragmatics , 1(1), pp. 11-45. DOI: https://doi.org/10.1515/soprag-2012-0008

14. Carrera de la Red, M. y Herrán Santiago, A. (2007): Oralidad en el universo de los discursos jurídico-administrativos en la Nueva Granada del siglo XVIII. En Cortés Rodríguez, L. (Coord.), Discurso y oralidad: homenaje al profesor José Jesús de Bustos Tovar (Vol. 1, pp. 333-349). Madrid: Arco Libros.

15. Castillo Gómez, A. y Sierra, V. (Dirs.) (2014): Cartas-Lettres-Lettere. Discursos, prácticas y representaciones epistolares (siglos XIV-XX). Alcalá de Henares: Universidad de Alcalá.

16. Cruz Volio, M. G. (2017): Actos de habla y modulación discursiva en español medieval. Representaciones de (des)cortesía verbal histórica. Berlin: Peter Lang. DOI: https://doi.org/10.3726/b11018

17. Fuentes Rodríguez, C. (2010): La Gramática de la Cortesía en Español/LE. Madrid: 
Arco Libros.

18. Fuentes Rodríguez, C. y Alcaide Lara, E. R. (Eds.) (2008): (Des)Cortesía, Agresividady Violencia Verbal en la Sociedad Actual. Sevilla: Servicio de Publicaciones de la Universidad Internacional Andalucía.

19. Fuentes Rodríguez, C. y Alcaide Lara, E. R, (Eds.) (2009): Manifestaciones Textuales de la (Des)Cortesía y Agresividad Verbal en Diversos Ámbitos Comunicativos. Sevilla: Servicio de Publicaciones de la Universidad Internacional Andalucía.

20. Gancedo Ruiz, M. (2018): Una primera aproximación al análisis diacrónico de la atenuación y la imagen en diálogos madre-hijo en el teatro español en los siglos XIX y XX. Estudios de Lingüística (ELUA), Anexo IV, pp. 157-178. DOI: https://doi.org/10.14198/ELUA2018.Anexo4.09

21. Gancedo Ruiz, M. (2019): Evolución de la imagen de rol familiar en el teatro de finales del siglo XIX a mitad del XX. Su manifestación en la atenuación e intensificación de los actos directivos. Tesis Doctoral inédita. Recuperado de: http://hdl.handle.net/10550/69590

22. Gancedo Ruiz, M. (2020): La evolución de la imagen de rol social familiar a través de la modulación pragmática de los actos de habla directivos en el teatro de los siglos XIX y XX. Estudio de la atenuación e intensificación en los roles de padre, madre e hijo. Pragmática Sociocultural / Sociocultural Pragmatics, 8(1), pp. 41-75. DOI: https://doi.org/10.1515/soprag-2020-0002

23. Haverkate, H. (1994): La cortesía verbal. Estudio pragmalingüístico. Madrid: Gredos.

24. Haverkate, H. (2001): Cortesía y descortesía en los diálogos del Quijote. Análisis de la representación de las imágenes positiva y negativa de los protagonistas. Oralia, 4, pp. 129-148.

25. Helfrich, U. y Pano Alamán, A. (2018): Introducción: la atenuación en los discursos digitales en español. Círculo De Lingüística Aplicada a La Comunicación, 73, pp. 514. DOI: https://doi.org/10.5209/CLAC.59056

26. Herrero Ruiz De Loizaga, F. J. (1999): El coloquio en el siglo XVI: cortesía, tratamiento y vocativos en la Segunda Celestina de Feliciano de Silva. Oralia, 2, pp. 221-240.

27. Herrero Ruiz De Loizaga, F. J. (2007): El insulto en la comedia celestinesca, en Cortés L., Bañón, A. M., Espejo, M. M. y Muñío J. L. (Coords.), Discurso y oralidad: homenaje al profesor José Jesús de Bustos Tovar. Anejo 3 de Oralia (Vol. 1, pp. 349-365). Madrid: Arco Libros.

28. Herrero Ruiz De Loizaga, F. J. (2013): El insulto en las obras dialogadas de los siglos XVI y XVII. En Pérez-Salazar, C., Tabernero Sala, C., y Usunáriz Garayoa, J. M. (Coords.), Los poderes de la palabra: el improperio en la cultura hispánica del Siglo de Oro (pp. 149-173). Peter Lang.

29. Iglesias Recuero, S. (2010): Aportación a la historia de la cortesía. Las peticiones en el siglo XVI, en Orletti, F. y Mariottini, L. (Eds.), (Des)cortesía en español: espacios teóricos y metodológicos para su estudio (pp. 369-396). Roma/Estocolmo: Università degli Studi Roma Tre-EDICE-Universidad de Estocolmo.

30. Iglesias Recuero, S. (2016): Otra cara de la pragmática histórica: la historia de los actos de habla en español. Peticiones y órdenes en las Novelas ejemplares de Cervantes. En López Serena, A. et al. (Dirs.): El español a través de los tiempos. Estudios ofrecidos a Rafael Cano, (Vol. 2, 971-994). Sevilla: Universidad de Sevilla.

31. Iglesias Recuero, S. (2017): Mecanismos de atenuación en las peticiones: de ayer a hoy, LEA: Lingüística Española Actual, 39(2), pp. 289-316.

32. Iglesias Recuero, S. (2018): Pragmática histórica: una breve historia de la expresión de peticiones y otros actos directivos en español. Ponencia plenaria pronunciada en el XI Congreso Internacional de Historia de la Lengua Española (Lima, 6-10 de agosto de 2018) (en prensa).

33. Jacobs, A., y A. H. Jucker (1995): The historical perspective in pragmatics. En Jucker, A. H. (Ed.), Historical pragmatics. Pragmatic developments in the History of English (pp. 3-33). Amsterdam/Philadelphia: John Benjamins. DOI: https://doi.org/10.1075/pbns.35.04jac

34. King, J. (2010): Pleas from the New World: The structure of directive head acts in Colonial Spanish familiar letters. Journal of Historical Pragmatics, 10, pp. 250-279. 


\section{DOI: https://doi.org/10.1075/jhp.11.2.04kin}

35. King, J. (2012): Early Modern Spanish Request Modifications as Politeness Strategies: Implications for the Study of Register. En Fernández Amaya, L. et al. (Eds.): New perspectives on (im)politeness and interpersonal communication (pp. 138-156), Cambridge: Cambridge Scholars Publishing.

36. Leal Abad, E. (2011): La fuerza ilocutiva en los debates medievales castellanos de controversia y su plasmación lingüística. E-Spania (online).

37. Leech, G. N. (2014): The pragmatics of politeness. Oxford: Studies in Sociolinguistics. DOI: https://doi.org/10.1093/acprof:oso/9780195341386.001.0001

38. Martínez Pasamar, C. (2019): Fenómenos de covariación lingüística en cartas del siglo XIX: las estrategias de intensificación y otras dimensiones de la variación. En Castillo Lluch, M. y Diez del Corral, E. (Eds.), Reescribiendo la historia de la lengua a partir de la edición de documentos (pp. 420-444). Bern: Peter Lang.

39. Martínez Pasamar, C. y Tabernero Sala, C. (2019): Reflexiones metodológicas sobre el tratamiento de la atenuación y la intensificación en corpus históricos: cartas privadas del siglo XIX. En González, R., Loureda, Ó. y Olza, I., (Eds.), Lengua, cultura, discurso. Estudios ofrecidos al profesor Manuel Casado Velarde (pp. 429-445). Pamplona: EUNSA.

40. Moreno González, M. C. (2002): La cortesía verbal en el Siglo de Oro: los actos de habla defectivos. En Echenique, M. T. y Sánchez Méndez, J. (Eds.), Actas del V Congreso Internacional de Historia de la Lengua Española (pp. 1347-1359). Madrid: Gredos.

41. Moreno González, Maㅡ C. (2008): Análisis diacrónico de la cortesía verbal del español clásico al contemporáneo. En Briz, A., Hidalgo, A., Albelda, M., Contreras, J. y Hernández Flores, N. (Eds.), Cortesía y conversación: de lo escrito a lo oral (pp. 410-418). Universidad de Valencia/EDICE: Valencia/Estocolmo.

42. Palander-Collin, M. y Nevala, M. (Eds.) (2005): Letters and Letter Writing. Número especial del European Journal of English Studies 9(1). DOI: https://doi.org/10.1080/13825570500067903

43. Pons Rodríguez, L. y Octavio de Toledo, A. S. (2016): Queja política y escritura epistolar durante la Guerra de Independencia: documentación de la Junta Suprema Central en el AHN. Selección, edición y estudio lingüístico. Madrid: Universidad de Alcalá.

44. Ramírez Luengo, J. L. (2016): Documentación de archivo e historia de la lengua: una reflexión desde el caso colombiano. Revista lingüística y literatura, 70, pp. 87117. DOI: https://doi.org/10.17533/udea.lyl.n70a04

45. Sáez Rivera, D. (2015): El secretario español de Carlos Pellicer como protopragmática y catálogo de los tratamientos nominales y pronominales del español del siglo XIX. Études Romanes de Brno, 36, pp. 119-148.

46. Salinas, P. (2002 [1948]): El defensor. Madrid: Alianza Editorial.

47. Schrott, A. (2000): ¿Quí los podrié contar? Interrogative acts in the Cantar de mio Cid: Some examples form Old Spanish on asking questions. Journal of Historical Pragmatics, 1(2), pp. 263-299. DOI: https://doi.org/10.1075/jhp.1.2.06sch

48. Searle, J. R. (1969): Actos de habla. Madrid: Cátedra.

49. Tabernero Sala, C. (2019): Fórmulas de cortesía y mecanismos de atenuación en la retórica epistolar del siglo XIX. En Castillo Lluch, M. y Diez de Corral, E. (Eds.), Reescribiendo la historia de la lengua a partir de la edición de documentos. Bern: Peter Lang, 391-419.

50. Tabernero Sala, C. (2020): Larga he sido pero no cuanto deseo: las mujeres como redactoras de cartas en la cultura escrita de la Edad Moderna. En Stefan, S. A. (Ed.), Curiosidad y censura en la Edad Moderna (pp. 5-36). Bucarest: Servicio de Publicaciones de la Universidad de Bucarest.

51. Wesch, A. (1996): Tradiciones discursivas en documentos indianos del S.XVI: sobre la estructuración del mandato en ordenanzas e instrucciones. En Alonso González, A. et al. (Coords.), Actas del III Congreso Internacional de Historia de la Lengua Española (Vol. 1, pp. 955-967). Madrid: Arco Libros. 